\title{
Effect of dietary L-carnitine supplementation to sows during gestation and/or lactation on sow productivity, muscle maturation and lifetime growth in progeny from large litters
}

\author{
Hazel B. Rooney ${ }^{1,2}$, K. O’Driscoll ${ }^{1}$, P. Silacci ${ }^{3}$, G. Bee ${ }^{3}$, J. V. O’Doherty ${ }^{2}$ and P. G. Lawlor ${ }^{1 *}$ \\ ${ }^{1}$ Pig Development Department, Animal and Grassland Research and Innovation Centre, Teagasc, Moorepark, Fermoy, Co. Cork \\ P61 C996, Republic of Ireland \\ ${ }^{2}$ School of Agriculture and Food Science, University College Dublin, Belfield, Dublin 4 D04 W6FG, Republic of Ireland \\ ${ }^{3}$ Institute for Livestock Sciences, Agroscope, Tioleyre, 1725 Posieux, Switzerland
}

(Submitted 24 September 2019 - Final revision received 31 January 2020 - Accepted 18 February 2020 - First published online 4 March 2020)

\section{Abstract}

Genetic selection for increased sow prolificacy has resulted in decreased mean piglet birth weight. This study aimed to investigate the effect of $\mathrm{L}$-carnitine (CAR) supplementation to sows during gestation and/or lactation on sow productivity, semitendinosus muscle (STM) maturity and lifetime growth in progeny. Sixty-four sows were randomly assigned to one of the four dietary treatments at breeding until weaning: CONTROL (0 mg CAR/d), GEST (125 mg CAR/d during gestation), LACT (250 mg CAR/d during lactation) and BOTH (125 mg CAR/d during gestation and $250 \mathrm{mg} \mathrm{CAR} / \mathrm{d}$ during lactation). The total number of piglets born per litter was greater for sows supplemented with CAR during gestation (17.3 v. 15.8 (sем 0.52); $P<0.05$ ). Piglet birth weight (total and live) was unaffected by sow treatment $(P>0 \cdot 05)$. Total myofibre number $(P=0.08)$ and the expression level of selected myosin heavy chain genes in the STM $(P<0.05)$ were greater in piglets of sows supplemented with CAR during gestation. Pigs from sows supplemented with CAR during gestation had lighter carcasses at slaughter than pigs from nonsupplemented sows during gestation $(83.8 v .86 .7$ (SEM 0.86) kg; $P<0.05)$. In conclusion, CAR supplementation during gestation increased litter size at birth without compromising piglet birth weight. Results also showed that the STM of piglets born to sows supplemented with CAR during gestation was more developed at birth. However, carcass weight at slaughter was reduced in progeny of sows supplemented with CAR during gestation. The CAR supplementation strategy applied during gestation in this study could be utilised by commercial pork producers to increase sow litter size and improve offspring muscle development.

Key words: Gestation supplementation: Hyper-prolificacy: Lactation supplementation: L-Carnitine: Muscle development

Litter size at birth and individual piglet birth weight are traits of economic importance in commercial pig production. As a consequence of continued genetic selection for increased sow prolificacy, litter size and the proportion of low-birth weight piglets within the litter have markedly increased ${ }^{(1)}$, suggesting that the nutritional supply for gestating sows requires improvement. Compared with their heavier littermates, low-birth weight piglets are less mature at birth, as indicated by lower proportions of fat and protein and more water in the body, and may be exposed to different degrees of intra-uterine growth restriction ${ }^{(2,3)}$. Piglets suffering from intra-uterine growth restriction may exhibit irregular growth, characterised by normal growth of the brain and restricted growth of other organs such as the heart, and this is known as the 'brain-sparing' effect ${ }^{(4)}$. Light-weight piglets also experience impaired growth during the suckling and grower-finisher stages, which is associated with a reduced total number of muscle fibres at birth ${ }^{(2,5)}$. Pigs that exhibit a reduced number of muscle fibres at birth and throughout their lifetime have a reduced potential for lean accretion, resulting in increased fat deposition and reduced lean meat yield at market age ${ }^{(6)}$. Optimising the productivity of sows and increasing the postnatal growth rates of piglets are two approaches that could be used to improve the performance of piglets from large litters.

L-Carnitine (CAR) is a water-soluble quaternary amine (3-hydroxy-4- $N, N, N$-trimethylaminobutyric acid) ${ }^{(7)}$. The most

Abbreviations: ADFI, average daily feed intake; ADG, average daily gain; BF, back-fat thickness; BW, body weight; CAR, L-carnitine; CS, citrate synthase; CF, cross-fostered; DE, digestible energy; FCE, feed conversion efficiency; HAD, $\beta$-hydroxyacyl-CoA dehydrogenase; IGF-1, insulin-like growth factor 1 ; LDH, lactate dehydrogenase; MyHC, myosin heavy chain; PW, post-weaning; STM, semitendinosus muscle; STM $_{\mathrm{d}}$, dark portion of the STM; STM , light portion of the STM.

* Corresponding author: P. G. Lawlor, email Peadar.lawlor@teagasc.ie 
recognised function of CAR is its vital role in the transport of medium- and long-chain fatty acids across the mitochondrial membrane where energy is generated through fatty acid oxidation $^{(8)}$. Supplementing gestating sow diets with CAR increased the number of fetuses and piglets born alive per $\operatorname{litter}^{(9,10)}$, and increased litter, fetal and individual piglet birth weight $^{(11-13)}$. Supplementation of CAR to sow diets during lactation increased milk yields during mid and late lactation and increased the concentration of protein, lactose and energy secreted in milk ${ }^{(14)}$. However, most research on the addition of CAR to sow diets was published over a decade ago, and significant increases in sow litter size since these studies were conducted may invalidate previous findings ${ }^{(15)}$. It is therefore important to determine if CAR can still provide a beneficial effect when supplemented to high genetic merit sows. The sows demand for nutrients and energy, needed to support fetal growth and milk production, has likely increased in parallel with the increase in litter size ${ }^{(16)}$. As such, there is a greater need for a dietary supplement that can increase overall sow and in utero nutrition; and because CAR is linked with fatty acid $\beta$-oxidation and energy production, it has the potential to benefit highperforming sows. Supplementing gestating sow diets with CAR has also been shown to improve fetal muscle fibre hyperplasia ${ }^{(17)}$. However, we are unaware of any study that has looked at the effects of CAR supplementation to multiparous sows on piglet muscle fibre development and muscle maturity at birth and at weaning, as well as subsequent lifetime growth of progeny.

Based on previous studies in sows, we hypothesised that supplementing CAR to high genetic merit sows would increase piglet birth weight and muscle fibre number, and improve muscle maturity in progeny at birth and at weaning. An increase in muscle fibre number in progeny from sows supplemented with CAR during gestation and/or lactation would likely contribute to an improvement in their lifetime growth and carcass quality at slaughter. Furthermore, we hypothesised that supplementing sows with CAR during lactation would increase the concentration of nutrients in sows' milk. To investigate these hypotheses, we investigated the effect of dietary CAR supplementation to high genetic merit multiparous sows during gestation and/or lactation on sow productivity and milk composition. Semitendinosus muscle (STM) maturation at birth and at weaning and lifetime growth in sow progeny were also examined.

\section{Experimental methods}

The study was carried out between June 2017 and June 2018, at the Teagasc pig research facility at Moorepark, Fermoy, Co. Cork, Ireland. Ethical approval for this study was granted by the Teagasc Animal Ethics Committee (approval no. TAEC150/2017), and the project was authorised by the Health Products Regulatory Authority (project authorisation no. AE19132/P064). The experiment was conducted in accordance with Irish legislation (SI no. 543/2012) and the EU Directive 2010/63/EU for animal experimentation. The health and welfare status of all animals used in this study was monitored daily.

\section{Animals, housing and treatments}

Sixty-four multiparous sows with the same genetic background (Large White $\times$ Landrace; Hermitage Genetics) were used in the study. Sows were artificially inseminated at the beginning of standing oestrus and again $24 \mathrm{~h}$ later using pooled semen (Danish Duroc; Hermitage Genetics). Gestating sows were housed in a dynamic group pen with fully slatted floors, insulated concrete lying bays and two electronic sow feeders (Schauer Feeding System (competent 6)). Water was available ad libitum from single-bite drinkers in the electronic sow feeders and from five drinker bowls located around the pen. The group pen held 120 animals at any one time. Sows selected from four weaning batches were inseminated at 3-week intervals, with twelve, sixteen, ten and twenty-six sows per batch. Five days before service, sows were blocked within batch into sixteen blocks of four sows on the basis of parity (mean 2.4 (SEM $0 \cdot 82)$ ), body weight (BW; mean 230.6 (SEM 24.26) kg) and back-fat thickness (BF; mean 13.9 (SEM 2.86) mm). Within each block, sows were randomly allocated to one of the four dietary treatments at breeding until weaning: (1) CONTROL (0 mg CAR/d; $n$ 16), (2) GEST (125 mg CAR/d during gestation; $n$ 16), (3) LACT ( $250 \mathrm{mg} \mathrm{CAR/d} \mathrm{during} \mathrm{lactation;} n$ 16) and (4) BOTH (125 mg CAR/d during gestation and $250 \mathrm{mg} \mathrm{CAR} / \mathrm{d}$ during lactation; $n 16$ ). Six days before sows were due to farrow they were moved into standard farrowing crates (pen dimensions: $2.5 \mathrm{~m} \times 1.8 \mathrm{~m}$ ). Farrowing rooms accommodated seven or fourteen animals per room, and temperature was maintained at approximately $24^{\circ} \mathrm{C}$ at farrowing and gradually reduced to $21^{\circ} \mathrm{C}$ by day 7 of lactation. Artificial lighting was provided daily from 08.00 to 16.30 hours. Where possible, litter size was standardised during the first $24 \mathrm{~h}$ postpartum, based on piglet $\mathrm{BW}$ and within treatment, to reduce variation in litter size and to reduce $\mathrm{BW}$ variation within litters. The final number of piglets remaining on each litter at $24 \mathrm{~h}$ postpartum was partially affected by the rearing capacity of each sow and the availability of foster sows to take surplus piglets. Piglets' teeth were clipped within $24 \mathrm{~h}$ postpartum, and tails were docked on day 3 postpartum. All piglets received an Fe injection on day 5 postpartum and males remained fully intact. Piglets were weaned on day 27 (SEM 1.2) of lactation.

All pigs were grouped by sow treatment and sex at weaning, and a sub-sample of 168 pigs (eighty-four females and eightyfour males) was then selected for the post-weaning (PW) growth phase of the trial. The pigs selected at weaning were those that represented the average weaning weight of each sow treatment, balanced equally for sex. Then, within each group, pigs were randomly assigned to the same sex pen groups of twelve pigs and moved to weaner accommodation (fourteen pen groups created; pen dimensions: $2.1 \mathrm{~m} \times 3.0 \mathrm{~m}$ ). Sow treatments were represented in each pen, with three pigs per sow treatment per pen. Pens were equipped with an automatic feeder and an individual pig recognition system (Schauer Agrotronic $\mathrm{GmbH}$ ). To allow pigs time to adapt to the automatic feeding system, feeders were switched off for the first $7 \mathrm{~d}$ and then switched to training mode for a further $7 \mathrm{~d}$. Individual feed intake was recorded after the adaptation period by the control software linked to each feeder (MLP; Schauer). Weaner room temperature 
was maintained at $28^{\circ} \mathrm{C}$ for the first $7 \mathrm{~d} \mathrm{PW}$ and gradually reduced to $22^{\circ} \mathrm{C}$ by day $28 \mathrm{PW}$. On day $49 \mathrm{PW}$, pig groups were moved to finisher accommodation (pen dimensions: $4.0 \mathrm{~m} \times 2.8 \mathrm{~m}$ ) which had the same layout and feeding system as the weaner housing. Finisher room temperature was maintained at $20-22^{\circ} \mathrm{C}$. Pig growth and feed intake was monitored to slaughter. Pigs in each batch were slaughtered at the same age (average time to slaughter $=146 \cdot 5($ sem 0.06) $\mathrm{d})$. Pigs were transported $95 \mathrm{~km}$ to a commercial abattoir (Dawn Pork and Bacon) where they were killed by exsanguination after $\mathrm{CO}_{2}$ stunning.

\section{Diets and feeding}

Diets were formulated to meet or exceed National Research Council ${ }^{(18)}$ recommendations. The ingredient composition and nutrient content of gestation and lactation diets are shown in Table 1. The electronic sow feeder (Schauer Feeding System) recognised individual animals by their transponder, which was programmed with the sows' dietary treatment and daily feed allowance $(2 \cdot 19 \mathrm{~kg} / \mathrm{d}$ from day 0 to day 90 of gestation, increasing to $2.65 \mathrm{~kg} / \mathrm{d}$ from day 90 of gestation to parturition). In the farrowing room, all diets were fed using a computerised

Table 1. Composition of experimental diets (on an air dry basis)

\begin{tabular}{|c|c|c|}
\hline Experimental diet & Gestation diet & Lactation diet \\
\hline \multicolumn{3}{|l|}{ Ingredients (g/kg) } \\
\hline Wheat & 0.0 & $367 \cdot 0$ \\
\hline Barley & 753.0 & $318 \cdot 1$ \\
\hline Soyabean meal (480 g/kg CP) & $89 \cdot 6$ & $196 \cdot 6$ \\
\hline Soya oil & $11 \cdot 0$ & $84 \cdot 0$ \\
\hline Lysine $\mathrm{HCl}(78 \cdot 8)^{*}$ & $2 \cdot 2$ & 2.9 \\
\hline DL-Methionine* & 0.6 & 0.8 \\
\hline L-Threonine $(98)^{*}$ & 0.6 & 1.4 \\
\hline L-Tryptophan* & 0.0 & 0.5 \\
\hline L-Valine* & 0.0 & $1 \cdot 3$ \\
\hline Di-calcium phosphate & $6 \cdot 5$ & 9.5 \\
\hline Limestone flour & $9 \cdot 1$ & 11.5 \\
\hline Salt & 4.0 & $4 \cdot 8$ \\
\hline Minerals and vitamins $†$ & 1.5 & 1.5 \\
\hline Phytase 5000 (IU/g)‡ & 0.1 & 0.1 \\
\hline \multicolumn{3}{|l|}{ Analysed nutrient composition $(\mathrm{g} / \mathrm{kg}$ ) } \\
\hline DM & $887 \cdot 0$ & $886 \cdot 0$ \\
\hline Ash & $42 \cdot 0$ & $44 \cdot 0$ \\
\hline Crude protein & $135 \cdot 0$ & $156 \cdot 0$ \\
\hline Diethyl ether extract & $36 \cdot 7$ & $87 \cdot 6$ \\
\hline Crude fibre & $63 \cdot 0$ & $27 \cdot 0$ \\
\hline Lysine & $7 \cdot 8$ & $9 \cdot 6$ \\
\hline Methionine & 2.4 & $2 \cdot 7$ \\
\hline Threonine & 4.9 & $6 \cdot 2$ \\
\hline Gross energy $(\mathrm{MJ} / \mathrm{kg})$ & $16 \cdot 1$ & $17 \cdot 6$ \\
\hline Digestible energy $(\mathrm{MJ} / \mathrm{kg}) \S$ & $12 \cdot 8$ & $14 \cdot 6$ \\
\hline
\end{tabular}

$\mathrm{CP}$, crude protein

* Synthetic amino acids.

† Mineral and vitamin premix provided per $\mathrm{kg}$ of complete diet: $\mathrm{Cu}, 15 \mathrm{mg}$ as copper sulphate; $\mathrm{Fe}, 70 \mathrm{mg}$ as ferrous sulphate monohydrate; $\mathrm{Mn}, 62 \mathrm{mg}$ as manganese oxide; $\mathrm{Zn}, 80 \mathrm{mg}$ as zinc oxide; iodine, $0.6 \mathrm{mg}$ as potassium iodate; Se, $0.2 \mathrm{mg}$ as sodium selenite; vitamin $A, 3 \mathrm{mg}$; vitamin $\mathrm{D}_{3}, 25 \mu \mathrm{g}$; vitamin $\mathrm{E}, 67 \mathrm{mg}$; vitamin $\mathrm{K}$, $2 \mathrm{mg}$; vitamin $B_{12}, 0.015 \mathrm{mg}$; riboflavin, $5 \mathrm{mg}$; nicotinic acid, $12 \mathrm{mg}$; pantothenic acid, $10 \mathrm{mg}$; choline chloride, $500 \mathrm{mg}$; biotin, $0.2 \mathrm{mg}$; folic acid, $5 \mathrm{mg}$; thiamin, $2 \mathrm{mg}$; pyridoxine, $3 \mathrm{mg}$.

‡ Sow diets contained 500 phytase units (FYT) per kg finished feed from Natuphos 5000 (RONOZYME HiPhos, DSM).

$\S$ Calculated value using prediction equations ${ }^{(19)}$ feed delivery system (DryExact Pro, Big Dutchman). Once farrowed, sows received a standard lactation diet (Table 1). Sows were fed twice daily from day 0 to day 6 of lactation and three times daily thereafter until day 27 of lactation. The sow lactation feed curve started at $60 \mathrm{MJ}$ digestible energy (DE)/d at day 0 of lactation and gradually increased to 107 , 125,133 and $140 \mathrm{MJ} \mathrm{DE} / \mathrm{d}$ at day 7, day 14, day 21 and day 27 of lactation, respectively. Water was provided on an ad libitum basis to sows from a single-bite drinker in the feed trough and to suckling piglets from a bowl in the farrowing pen.

Suckling piglets did not receive creep feed. Following weaning, pigs were fed the following sequence of dry pelleted diets $(3 \mathrm{~mm}$ in diameter): starter diet ( $1.6 \%$ lysine, $16 \cdot 2 \mathrm{MJ}$ $\mathrm{DE} / \mathrm{kg}$ ) from day 0 to day $7 \mathrm{PW}$, link diet (1.5\% lysine, $15.0 \mathrm{MJ} \mathrm{DE} / \mathrm{kg}$ ) from day 7 to day $21 \mathrm{PW}$, weaner diet ( $1.3 \%$ lysine, $14.4 \mathrm{MJ} \mathrm{DE} / \mathrm{kg}$ ) from day 21 to day $49 \mathrm{PW}$ and finisher diet $(1 \cdot 1 \%$ lysine, $13 \cdot 8 \mathrm{MJ} \mathrm{DE} / \mathrm{kg})$ from day $49 \mathrm{PW}$ to slaughter (day $120 \mathrm{PW}$ ). Water was available on an ad libitum basis from a single drinker bowl in each pen in both weaner and finisher accommodation (DRIK-O-MAT, Egebjerg International $\mathrm{A} / \mathrm{S}$ ).

\section{L-Carnitine supplementation}

Sows on the GEST and BOTH treatments had their diets top dressed once a day during gestation with $30 \mathrm{~g}$ of a supplement that contained $0.25 \mathrm{~g}$ of Carniking (purity $50 \%$; Lonza Ltd) and $29.75 \mathrm{~g}$ of an inorganic carrier sepiolite (EXAL-H, TOLSA), to provide sows with $125 \mathrm{mg}$ of CAR/d. From day 0 to day 27 of lactation, sows on the LACT and BOTH treatments had their morning feed top dressed once a day with $60 \mathrm{~g}$ of the same supplement, to provide sows with $250 \mathrm{mg}$ of CAR/d. The CAR dosage was based on previous studies ${ }^{(11,12,14,20)}$.

\section{Sow and piglet measures}

Sow body weight and back-fat thickness. Sow BW and BF were recorded $5 \mathrm{~d}$ before service, on day 71 and day 108 of gestation, and again at weaning (approximately day 27 of lactation). Sow BW was recorded using an electronic sow scales (EziWeigh 7i; O'Donovan Engineering). Sow BF was measured using a digital back-fat indicator (Renco LEAN-MEATER; Renco Corporation) by placing the probe of the digital indicator on the back of the sow at the level of the second last rib, $6.5 \mathrm{~cm}$ from the side of the backbone. A reading was taken from the right and left sides of the sows back, and the average of both readings was recorded.

Lactation feed intake. Individual feed intake of sows during lactation was recorded daily, from which the total lactation feed intake and average daily feed intake (ADFI) for each sow were calculated.

Litter data at birth and pre-weaning piglet growth performance. The number of piglets born (total, live, stillborn and mummified) was recorded for each litter at birth. The weight and sex of each piglet were recorded at birth, and each piglet was tagged for identification purposes. Thereafter, 
piglets were individually weighed on day 1, day 14 and day 27 postpartum, and these data were used to determine preweaning piglet average daily gain (ADG), litter size and litter weight. Piglet mortality between birth and weaning was also recorded.

Post-weaning pig growth performance. Pigs were individually weighed on day 0 , day 7 , day 14 , day 28 and day 49 PW, and at slaughter (day $120 \mathrm{PW}$ ). Pigs were not fasted before weighing. Feed intakes were recorded on an individual basis from day $14 \mathrm{PW}$ to slaughter. These data were used to determine the ADG, ADFI and feed conversion efficiency (FCE) for each individual pig. At the abattoir, carcass cold weight was calculated by multiplying the hot carcass weight, recorded within $45 \mathrm{~min}$ of the pig being exsanguinated, by 0.98. Carcass BF thickness and muscle depth, measured from the edge of the split back at the level of the third and fourth last rib, were determined using a Hennessy Grading Probe (Hennessy and Chong). Lean meat content was estimated according to the following formula: estimated lean meat content $(\%)=60 \cdot 3-0 \cdot 847 x+0 \cdot 147 y$, where $x=$ fat depth $(\mathrm{mm}) ; y=$ muscle depth $(\mathrm{mm})^{(21)}$.

\section{Blood, milk and tissue measurements}

Collection and analysis of sow blood samples. On day 71 and day 102 of gestation and at weaning, blood samples for the analysis of insulin-like growth factor 1 (IGF-1) and insulin were collected from a subset of sows by jugular venepuncture (n 32 sows). Blood samples were collected into $9 \mathrm{ml}$ EDTA collection tubes and into $9 \mathrm{ml}$ serum clot activator collection tubes (VACUETTE ${ }^{\circledR}$, Labstock Microservices). EDTA blood tubes were immediately centrifuged after collection at $3000 \mathrm{rpm}$ for $15 \mathrm{~min}$ at room temperature for plasma collection, and serum clot activator tubes were centrifuged $24 \mathrm{~h}$ later under the same conditions. After centrifuging, the serum/plasma layer was removed from the blood cell layer and samples were then stored at $-20^{\circ} \mathrm{C}$ until analysis. Plasma and serum samples were analysed in duplicate for concentrations of IGF-1 and insulin, respectively, using commercial ELISA kits (Mediagnost IGF-1 ELISA kit, Oxford Biosystems; Human Insulin ELISA kit, Fisher Scientific). Plasma samples were diluted 1:21 with sample buffer prior to analysis. Serum samples were not diluted. The minimum detectable concentration of IGF-1 and insulin that could be distinguished from 0 was $0.09 \mu \mathrm{g} / 1$ and $0.17 \mu \mathrm{IU} / \mathrm{ml}$, respectively. Intra-assay $\mathrm{CV}$ were 4.8 and $3.8 \%$, and inter-assay $\mathrm{CV}$ were $9 \cdot 1$ and $9 \cdot 7 \%$ for IGF-1 and insulin, respectively. IGF-1 and insulin concentrations were quantified by interpolating absorbance readings from a standard curve generated in the same assay.

\section{Collection and analysis of sow colostrum and milk samples.}

Colostrum samples were collected from sows within $3 \mathrm{~h}$ of the first piglet being born (about $15 \mathrm{ml} ; n 48$ sows). On day 14 of lactation, milk samples were collected from sows (about $30 \mathrm{ml} ; n 52$ sows) following a $1 \mathrm{ml}$ (10 IU) intramuscular injection of Oxytocin (Eurovet Animal Health). Colostrum and milk samples were collected and stored as previously described by Rooney et al $^{(22)}$. Colostrum samples were diluted 1:4 with distilled deionised water prior to analysis and then analysed in duplicate for the percentage of total solids, protein, fat, lactose and ash on an infrared analyser (Bentley DairySpec FT 89111; Bentley Instruments). Undiluted milk samples were analysed in duplicate for the percentage of total solids, protein, fat and lactose on another infrared analyser (Milkoscan FT 6000; Foss Electric). Sow milk yield was estimated by assuming $4 \mathrm{~kg}$ of milk produced per $\mathrm{kg}$ of litter weight gain between day 1 postpartum and weaning ${ }^{(23,24)}$.

Blood and semitendinosus muscle collection from euthanised piglets. At birth, one male piglet and one female piglet representing the average birth weight of the litter were selected from twenty-four litters (six litters per treatment; $n 48$ piglets). The same sampling procedure was replicated at weaning (six litters per treatment; $n 48$ piglets). Pigs were stunned by penetrative captive bolt (Punch Bolt Stunner; Mac Eoin General Merchants Ltd), then euthanised by exsanguination. Blood samples for the analysis of IGF-1 and insulin were collected at the point of exsanguination into $5 \mathrm{ml}$ EDTA collection tubes and into $5 \mathrm{ml}$ serum clot activator collection tubes (VACUETTE ${ }^{\circledR}$; Labstock Microservices). Piglet blood glucose concentration was determined using a handheld blood glucose monitor (IDIA Blood Glucose Monitor; Arctic Medical), by inserting a glucose test strip into a fresh droplet of blood. Piglet blood samples were processed, stored and analysed under the same conditions as sow blood samples. Within 30 min of exsanguination, the entire STM was excised from the left carcass side of all piglets euthanised at birth and at weaning. The STM was then weighed, and its length and circumference were measured using a piece of string and a digital calliper (Digital Carbon Fibre Calipers; Fisher Scientific). The STM of the twenty-four female piglets euthanised at birth was dissected into the dark $\left(\mathrm{STM}_{\mathrm{d}}\right)$ and light $\left(\mathrm{STM}_{\mathrm{l}}\right)$ portion. From each muscle portion, a subsample was cut longitudinally to the muscle fibre, fixed onto a piece of labelled corkboard, dusted in talcum powder, snap frozen in liquid $\mathrm{N}_{2}$ and stored at $-80^{\circ} \mathrm{C}$ for histochemical, enzyme activity and gene expression analysis.

Histochemical analysis of the semitendinosus muscle. For myofibre determination, frozen muscle samples were temperature-equilibrated to $-20^{\circ} \mathrm{C}$, cut from the piece of corkboard, trimmed and then mounted on a cryostat chuck with a drop of embedding resin. Cross sections $(10-\mu \mathrm{m}$ thick) of the $\mathrm{STM}_{\mathrm{d}}$ and $\mathrm{STM}_{1}$ were cut perpendicular to the fibre direction at $-20^{\circ} \mathrm{C}$ in a Cyrotome (Shandon cryotome; Shandon, Inc.). Two sections per sample were mounted on a glass microscopic slide (Menzel-Gläser Superfrost Plus; Gerhard Menzel GmbH), air-dried for $30 \mathrm{~min}$ and stored at $-20^{\circ} \mathrm{C}$ until use. Sections were then stained using the following protocol. Frozen slides were fixed in methanol at $-20^{\circ} \mathrm{C}$ for $10 \mathrm{~min}$ and then allowed to dry at room temperature. Once dried, the slides were washed three times with $200 \mu$ l of PBS-Tween 20, 0.01\% (Vector Laboratories Ltd, Orton Southgate). Slides were then incubated for $1 \mathrm{~h}$ at room temperature with $200 \mu \mathrm{l}$ of rabbit anti-laminin (Sigma-Aldrich Chemie $\mathrm{GmbH}$ ) that was diluted 1:500 in PBS-Tween 20, $0.01 \%$ with $10 \%$ goat serum. After incubation, slides were washed three times with $250 \mu \mathrm{l}$ of PBS-Tween 20, $0 \cdot 01 \%$. Slides were then incubated for $20 \mathrm{~min}$ at room temperature with 
$200 \mu \mathrm{l}$ of goat anti-rabbit IgG-HRP conjugate (Sigma-Aldrich) that was diluted 1:100 in PBS-Tween 20, 0.01 with $10 \%$ goat serum. After the second incubation, slides were washed three times with $250^{\circ} \mu \mathrm{l}$ of PBS-Tween $20,0.01 \%$. Once slides were washed, $250 \mu \mathrm{l}$ of 3 '-diaminobenzidine (DAB) peroxidase substrate (Vector Laboratories Ltd) was added to each slide and slides were incubated for a further $10 \mathrm{~min}$ at room temperature. Slides were then washed in Milli-Q water (Milli-Q Integral Water Purification System; Merck) for $5 \mathrm{~min}$. Finally, the slides were fixed using two drops of VectaMount AQ mounting medium (Vector Laboratories Ltd) and a glass coverslip.

Subsequently, stained sections were observed at $20 \times$ and $40 \times$ magnifications using a BX50 microscope in transmitted light mode (Olympus Optical) equipped with a high-resolution digital camera (ColourView12, Soft Imaging system GmbH). Five to six random fields at different locations on the slide were captured as TIFF images, and a total of 700 myofibres were counted per muscle section. The average area of myofibres in the $\mathrm{STM}_{d}$ and $\mathrm{STM}_{1}$ was determined with the Olympus cellsens Dimension 1.16 imaging software (Olympus). The total muscle area (based on the STM circumference measured at the midpoint of the muscle) and the total area of the counted myofibres in the $\mathrm{STM}_{\mathrm{d}}$ and $\mathrm{STM}_{1}$ were then used to estimate the total number of myofibres in the entire STM. As an indicator of myofibre density, the number of myofibres was also expressed per $\mathrm{mm}^{2}$ in the STM.

Enzyme activity analysis in the semitendinosus muscle. To characterise the citric acid cycle activity, lipid oxidation and glycolytic capacity, activities of citrate synthase (CS; EC 4.1.3.7), $\beta$-hydroxyacyl-CoA dehydrogenase (HAD; EC 1.1.1.35) and lactate dehydrogenase (LDH; EC 1.1.1.27), respectively, were measured in the $\mathrm{STM}_{\mathrm{d}}$ and $\mathrm{STM}_{1}$ as previously described by Madsen et $a l .{ }^{(25)}$. In brief, protein was extracted from $100 \mu \mathrm{g}$ of muscle samples that were stored at $-80^{\circ} \mathrm{C}$. After lysis in $500 \mu \mathrm{l}$ of CelLytic MT buffer (Sigma-Aldrich Chemie GmbH), protein extracts were treated with Complete TM Inhibitor Cocktail Tablets (F. Hoffmann-La Roche Ltd), homogenised and centrifuged. Protein concentration was then determined with the Pierce Coomassie Plus (Bradford) Assay Kit (Thermo Scientific). The HAD activity was determined at $340 \mathrm{~nm}$ with a spectrophotometer (Biochrom WPA Biowave II; Biochrom Ltd) as the change in light absorbance for $3 \mathrm{~min}$ at $37^{\circ} \mathrm{C}$. The activities of $\mathrm{LDH}$ and $\mathrm{CS}$ were determined with the $\mathrm{LDH}$ and CS BioVision Activity Colorimetric Assay Kits (Biovision Inc.). Activities of LDH and CS were measured at $450 \mathrm{~nm}$ for $10 \mathrm{~min}$ and at $412 \mathrm{~nm}$ for $30 \mathrm{~min}$, respectively. Samples were standardised per mg protein and enzyme activity expressed as substrate degradation in $\mu \mathrm{mol} / \mathrm{min}$.

Gene expression analysis in the semitendinosus muscle. Total RNA was extracted from muscle samples stored at $-80^{\circ} \mathrm{C}$ using the RNeasy Plus Universal Mini Kit (QIAGEN). Before column purification, tissues were treated with proteinase $\mathrm{K}$ to ensure complete lysis and a deoxyribonuclease one-digestion step during RNA purification was included to prevent contamination with genomic DNA. All RNA extraction steps were performed according to the manufacturer's protocol. The RNA concentration was assessed using the Qubit fluorometer (Qubit 4 Fluorometer; Thermo Scientific). The RNA quality was assessed by capillary electrophoresis using a fragment analyser (Advanced Analytical Technologies Inc.) and by measuring the absorbance ratio at $260 / 280 \mathrm{~nm}$ which was 1.82 and 2.29. The complementary DNA reverse transcription was performed using the Verso complementary DNA Synthesis kit (AB1453A; Thermo Scientific) with $1 \mu \mathrm{l}$ of an oligo (dT) primer in a final volume of $20 \mu$ l. The reverse transcription reaction was carried out under the following conditions: $30 \mathrm{~min}$ at $42^{\circ} \mathrm{C}$ and $3 \mathrm{~min}$ at $95^{\circ} \mathrm{C}$. Following reverse transcription, the complementary DNA was used to assess gene expression by quantitative PCR. The quantitative PCR primers were designed using the Primer-BLAST at the NCBI website (http://www.ncbi.nlm.nih. gov/tools/primer-blast) ${ }^{(26)}$ and subsequently purchased from Microsynth AG. The sequences of the primers are listed in online Supplementary Table S1. Primers chosen for myosin heavy chain (MyHC) genes were MyHC slow/I, MyHC IIa, MyHC IIx and MyCH IIb. All reactions were carried out in duplicate with an Eco Real-Time PCR System (Illumina) in a reaction volume of $20 \mu \mathrm{l}$. The expression of genes was assessed with the SYBR green technology with the following reaction mix: $10 \mu$ Kapa SYBR Fast Universal $2 \times$ quantitative PCR Master Mix (Kapa Biosystems), $7 \cdot 6 \mu \mathrm{l}$ of nuclease-free water, and $0.4 \mu \mathrm{l}$ of a water diluted mix containing $10 \mu \mathrm{mol} / \mathrm{l}$ forward and reverse primer and $2 \mu \mathrm{l}$ of complementary DNA (about $1 \mathrm{ng}$ ) were added as a template. The thermal profile was as follows: 5 min of activation at $95^{\circ} \mathrm{C}$, followed by forty cycles of a two-step PCR with $5 \mathrm{~s}$ denaturation at $95^{\circ} \mathrm{C}$ and $20 \mathrm{~s}$ combined annealing and extension at $60^{\circ} \mathrm{C}$. Gene expression was calculated as the relative expression of target genes in relation to one reference gene, EEF1A1, using the $\Delta \Delta C t$ - method corrected for amplification efficiency ${ }^{(27)}$.

\section{Statistical analysis}

A power calculation was performed to determine the minimum number of observations required to detect effect sizes, using a statistical power of $80 \%$, an $\alpha$ level at $5 \%$ and the standard deviation of similar variables of interest from seven previously published studies. The power calculation indicated that between twenty-seven and thirty-nine animals per treatment are necessary to see a difference of 1.4-1.8 piglets born per litter, and between twelve and sixteen animals per treatment are required to see a difference of $21-24\left(\times 10^{4}\right)$ muscle fibres in the STM. Statistical analysis was performed using linear mixed models (PROC MIXED) of the Statistical Analysis Systems software package version 9.4 (SAS Institute Inc.) for a two by two factorial arrangement. All data were tested for normality prior to analysis by examination of histograms and normal distribution plots using the Univariate procedure. Residuals were inspected in all models to confirm normality. Model fit was determined by choosing models with the minimum finite-sample-corrected Akaike Information Criteria. Differences in least square means were investigated using the $t$ test after Tukey adjustment for multiple comparisons. Using Satterthwaite adjustment, df were estimated. The sow was the experimental unit for sow and pre-weaning data analysis, and the pig was the experimental unit for PW growth performance data analysis. The statistical model included the main effects of 
gestation treatment, lactation treatment and their interaction, and sow batch was included as a fixed effect. Sow block was included as a random effect for analysis of sow and litter data, and pen and sow were included as random effects for analysis of PW pig data. For measures repeated over time, the time of recording was included in the model in the repeated statement. When significant in the model, the following covariates were included: initial sow $\mathrm{BW}$ and $\mathrm{BF}$ for analysis of subsequent sow $\mathrm{BW}$ and $\mathrm{BF}$, lactation length for analysis of sow lactation feed intake, number of pigs weaned for analysis of sow lactation feed intake and sow weight change during lactation, piglet birth weight for analysis of muscle measures, pen size for analysis of PW pig growth, pig age at slaughter for analysis of carcass cold weight, and pig live weight at slaughter for analysis of carcass fat depth, muscle depth, lean meat yield and kill out yield. When no significant interaction between gestation feeding and lactation feeding of CAR was observed for a variable of interest, the interaction was removed from the model. Results are presented in the text and tables as the least square means together with the pooled standard error. Differences between treatments were considered significant for $P<0.05$, whereas $0.05<P<0.10$ was discussed as a trend.

\section{Results}

All sows remained clinically healthy during the study duration, and no adverse events were observed in any of the experimental groups.

\section{Sow body weight and back-fat thickness}

There was no interaction between gestation and lactation feeding of CAR observed for sow BW and BF gain, and therefore, only the main effects are presented in Table 2 . There was no effect of CAR supplementation on sow BW between day 71 of gestation and weaning. Sow BF was similar across treatments on day 71 and day 108 of gestation. However, at weaning, BF tended to be lower in sows supplemented with CAR during gestation than sows that received no CAR during gestation $(P=0 \cdot 10)$. An interaction between gestation and lactation feeding of CAR was observed for sow BW loss between day 108 of gestation and weaning $(P=0 \cdot 04)$, whereby GEST sows lost more weight than CONTROL sows $(-27.5 v$. $-16.6($ SEM $3 \cdot 16) \mathrm{kg})$. However, when sow weight was corrected for the estimated empty weight of the sow at farrowing ${ }^{(28)}$, BW loss between farrowing and weaning was unaffected by treatment. There was no difference in sow BW loss between day 108 of gestation and weaning between LACT sows and BOTH sows $(-24.0 \mathrm{v}$. $-21.7($ sem 3.38$) \mathrm{kg}$ ). Sow BF loss between day 108 of gestation and weaning was unaffected by sow treatment (Table 2).

\section{Sow and piglet insulin, insulin-like growth factor 1 and glucose concentration}

Serum insulin, plasma IGF-1 and blood glucose concentrations for sows and piglets are presented in Table 3. Concentrations of sow serum insulin were not affected by treatment on day

Table 2. Effect of L-carnitine (CAR) supplementation to sows during gestation and lactation on sow body weight (BW) and back-fat thickness (BF) from day 71 of gestation to weaning, and sow body condition changes during lactation* (Mean values with their standard errors)

\begin{tabular}{|c|c|c|c|c|c|c|c|c|}
\hline \multirow{2}{*}{$\frac{\text { CAR }}{\text { Measure } \dagger}$} & \multicolumn{4}{|c|}{ Gestation (mg/d) } & \multicolumn{4}{|c|}{ Lactation (mg/d) } \\
\hline & 0 & 125 & SEM & $P$ & 0 & 250 & SEM & $P^{*}$ \\
\hline \multicolumn{9}{|l|}{ BW (kg) } \\
\hline Day 71 & $256 \cdot 2$ & 257.7 & $5 \cdot 61$ & 0.71 & & & & \\
\hline Day 108 & 280.9 & 283.6 & 5.61 & 0.47 & & & & \\
\hline Farrowing $\ddagger$ & $244 \cdot 2$ & $242 \cdot 7$ & 5.48 & 0.71 & & & & \\
\hline Weaning§ & 259.6 & 258.7 & 6.79 & 0.86 & 258.6 & 259.7 & $6 \cdot 91$ & 0.84 \\
\hline \multicolumn{9}{|l|}{$\mathrm{BF}(\mathrm{mm})$} \\
\hline Day 71 & $16 \cdot 9$ & $16 \cdot 1$ & 0.59 & 0.23 & & & & \\
\hline Day 108 & $17 \cdot 4$ & $16 \cdot 9$ & 0.71 & 0.48 & & & & \\
\hline Weaning & $15 \cdot 0$ & $13 \cdot 9$ & 0.70 & 0.10 & 14.6 & 14.3 & 0.72 & 0.71 \\
\hline \multicolumn{9}{|l|}{ Sow BW change (kg) } \\
\hline Day 108 to weaning $\| \rrbracket$ & $-20 \cdot 3$ & -24.6 & 2.31 & 0.18 & $-22 \cdot 0$ & -22.8 & $2 \cdot 36$ & 0.79 \\
\hline Farrowing to weaning ${ }^{\star *}$ & $+15 \cdot 2$ & +15.8 & 2.70 & 0.87 & +14.9 & $+16 \cdot 0$ & $2 \cdot 75$ & 0.76 \\
\hline \multicolumn{9}{|l|}{ Sow BF change $(\mathrm{mm})$} \\
\hline Day 108 to weaningt† & $-2 \cdot 8$ & $-2 \cdot 7$ & 0.35 & 0.81 & $-3 \cdot 1$ & $-2 \cdot 4$ & 0.35 & 0.19 \\
\hline
\end{tabular}

* Main effects of sow dietary treatment are presented in this table. Probability values at $P<0.05$ are considered significant and as tendencies at $P<0.10$.

$\dagger n 32$ sows per treatment.

¥ Estimated value: empty farrowing weight $=($ sow weight at day $108-($ total born $\times 2 \cdot 25)$ ). The value of $2 \cdot 25 \mathrm{~kg}$ is an estimate of the increased weight in the gravid uterus and mammary tissue attributed to each pig in a litter ${ }^{(28)}$.

$\S$ Weaning = approximately day 27 of lactation.

II Sow BW change $=$ (sow BW at weaning - sow BW at day 108 of gestation).

II Interaction between gestation and lactation feeding of CAR was observed for sow BW loss between day 108 of gestation and weaning; sows supplemented with CAR during gestation (GEST) lost more weight than sows that were not supplemented with CAR during gestation (CONTROL; $-27.5 \mathrm{v} .-16.6$ (SEM 3.16) kg; $P<0.05$ ). However, when sow weight was corrected for the estimated empty weight of the sow at farrowing, this result was non-significant. There was no difference in sow BW loss between sows supplemented with CAR during lactation (LACT) and those supplemented during gestation and lactation (BOTH; $-24.0 \mathrm{v} .-21.7$ (SEM 3.38) kg).

** Sow BW change $=$ (sow BW at weaning - estimated sow empty farrowing weight).

†† Sow BF change $=$ (sow BF at weaning - sow BF at day 108 of gestation $)$. 
Table 3. Effect of L-carnitine (CAR) supplementation to sows during gestation and lactation on the concentration of serum insulin and plasma insulin-like growth factor 1 (IGF-1) in sows and piglets, and piglet blood glucose concentration* (Mean values with their standard errors)

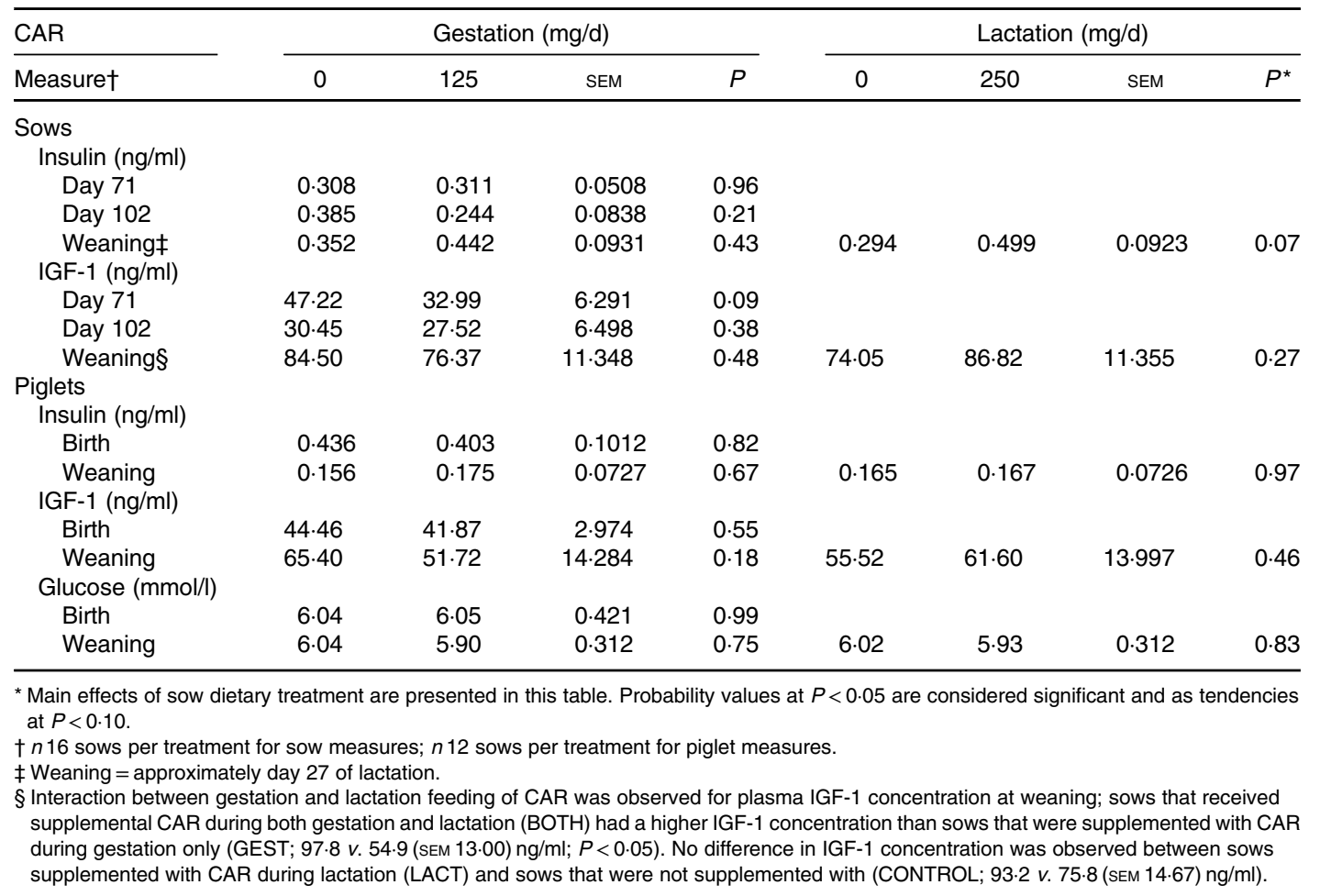

71 and day 102 of gestation, but subsequent to this, insulin levels at weaning tended to be higher in sows supplemented with CAR during lactation compared with sows that received no CAR during lactation $(P=0 \cdot 07)$. On day 71 of gestation, sows supplemented with CAR during gestation tended to have a lower concentration of plasma IGF-1 than sows that were not supplemented during gestation $(P=0.09)$. An interaction between gestation and lactation feeding of CAR was observed for plasma IGF-1 concentration at weaning $(P=0.02)$, whereby BOTH sows had a higher IGF-1 concentration than GEST sows $(97.82 v .54 .93$ (SEM 13.001) ng/ml). No difference in IGF-1 concentration was observed between LACT sows and CONTROL sows $(93.18 v .75 .83(\operatorname{sem} 14.67) \mathrm{ng} / \mathrm{ml})$. At birth and at weaning, the concentration of insulin, IGF-1 and glucose in the blood of euthanised piglets was not affected by sow dietary treatment.

\section{Colostrum and milk}

There was no effect of maternal CAR supplementation during gestation on the concentration of total solids (23.2 (SEM 0.44) \%), protein $(16.0($ SEM 0.40$) \%)$, fat $(3.9(\operatorname{sem} 0.26) \%)$ or ash (1.0 (SEM 0.01) \%) in sow colostrum. However, lactose concentration was lower in the colostrum of sows that were supplemented with CAR during gestation compared with that of nonsupplemented sows during gestation $(2 \cdot 1$ v. $2 \cdot 4$ (SEM 0.09)\%; $P=0.01$ ). Sow milk composition on day 14 of lactation did not differ between sow treatments. The average concentration of milk total solids, protein, fat and lactose was 17.4 (SEM 0.23)\%, 4.4 (SEM 0.06) \%, 7.1 (SEM 0.23) \% and 5.8 (SEM 0.04) \%, respectively.
Sow milk yield was also similar between sows supplemented and not supplemented with CAR during gestation and/or lactation. The average total sow milk yield during lactation was $304.8(\operatorname{SEM} 11.03) \mathrm{kg}$, equating to $11.7(\operatorname{SEM} 0.42) \mathrm{kg}$ milk produced/d.

\section{Lactation feed intakes}

Feed intake during lactation did not differ between supplemented and non-supplemented sows during gestation and/or lactation. The average total feed intake during lactation was 201.7 (SEm 1.63$) \mathrm{kg}$, equating to $7.4($ SEm 0.05$) \mathrm{kg}$ feed/d.

\section{Sow reproductive performance and piglet pre-weaning growth performance}

Maternal CAR supplementation during gestation increased the total number of piglets born $(P=0.03)$, yet had no effect on the number of pigs born alive, litter weight or individual piglet weight at birth (Table 4). Subsequently, there was no difference in individual piglet BW or litter weight and litter size on day 1 , day 14 and day 27 of lactation. The number of piglets cross fostered, piglet pre-weaning ADG and piglet mortality between day 1 and day 27 of lactation were also not affected by sow treatment (Table 5).

\section{Morphometric measurements and myofibre-related traits in the semitendinosus muscle}

The BW of piglets killed for muscle morphometric measurements at birth and at weaning was not affected by maternal 
Table 4. Effect of L-carnitine (CAR) supplementation to sows during gestation on the number of piglets born, litter weight at birth and individual piglet birth weight* (Mean values with their standard errors)

\begin{tabular}{lcccc}
\hline CAR & \multicolumn{4}{c}{ Gestation $(\mathrm{mg} / \mathrm{d})$} \\
\cline { 3 - 5 } Measure & 0 & 125 & SEM & $P^{*}$ \\
\hline Litter size at birth $(n)$ & & & & \\
$\quad$ Total born & 15.8 & 17.3 & 0.52 & 0.03 \\
$\quad$ Live born & 14.7 & 15.6 & 0.51 & 0.19 \\
$\begin{array}{l}\text { Litter weight at birth }(\mathrm{kg}) \\
\quad \text { Total born }\end{array}$ & 22.0 & 23.4 & 0.67 & 0.13 \\
$\quad$ Live born & 20.7 & 21.7 & 0.66 & 0.26 \\
Mean piglet birth weight $(\mathrm{kg})$ & 1.41 & 1.36 & 0.042 & 0.38 \\
$\quad$ Total born & 1.44 & 1.40 & 0.041 & 0.54 \\
$\quad$ Live born & & &
\end{tabular}

${ }^{*}$ Probability values at $P<0.05$ are considered significant and as tendencies at $P<0.10$. $\dagger n 32$ sows per treatment.

Table 5. Effect of $L$-carnitine (CAR) supplementation to sows during gestation and lactation on individual piglet body weight (BW), piglet average daily gain (ADG), litter size and litter weight, number of piglets cross-fostered (CF), and piglet mortality from day 1 to day 27 of lactation*

(Mean values with their standard errors)

\begin{tabular}{|c|c|c|c|c|c|c|c|c|}
\hline \multirow{2}{*}{$\frac{\text { CAR }}{\text { Measure } †}$} & \multicolumn{4}{|c|}{ Gestation (mg/d) } & \multicolumn{4}{|c|}{ Lactation $(\mathrm{mg} / \mathrm{d})$} \\
\hline & 0 & 125 & SEM & $P$ & 0 & 250 & SEM & $P^{*}$ \\
\hline \multicolumn{9}{|l|}{ Piglet BW (kg) } \\
\hline Day 1 & 1.51 & 1.46 & 0.048 & 0.96 & 1.50 & 1.47 & 0.048 & 0.99 \\
\hline Day 14 & 4.5 & $4 \cdot 2$ & 0.15 & 0.91 & 4.4 & $4 \cdot 3$ & 0.15 & 0.97 \\
\hline Day 27‡ & $7 \cdot 7$ & $7 \cdot 5$ & 0.26 & 0.99 & $7 \cdot 7$ & $7 \cdot 5$ & 0.26 & 0.99 \\
\hline \multicolumn{9}{|l|}{ Piglet ADG $(\mathrm{g} / \mathrm{d}) \S$} \\
\hline Day 0 to day 1 & 88 & 62 & 9.5 & 0.47 & 73 & 77 & $9 \cdot 5$ & 1.00 \\
\hline Day 1 to day 14 & 222 & 219 & $7 \cdot 1$ & 0.99 & 228 & 213 & $8 \cdot 1$ & 0.82 \\
\hline Day 14 to day 27 & 247 & 250 & $9 \cdot 6$ & 1.00 & 250 & 247 & $8 \cdot 2$ & 1.00 \\
\hline Day 0 to day 27 & 238 & 237 & $7 \cdot 3$ & 1.00 & 242 & 233 & $7 \cdot 1$ & 0.93 \\
\hline \multicolumn{9}{|l|}{ Litter sizell } \\
\hline Day 1 & $13 \cdot 5$ & 14.6 & 0.39 & 0.41 & $13 \cdot 5$ & 14.6 & 0.39 & 0.43 \\
\hline Day 14 & $12 \cdot 8$ & $13 \cdot 0$ & 0.35 & 0.99 & $12 \cdot 4$ & $13 \cdot 4$ & 0.35 & 0.34 \\
\hline Day 27 & $12 \cdot 4$ & $12 \cdot 5$ & 0.35 & 1.00 & $12 \cdot 0$ & $12 \cdot 9$ & 0.36 & 0.52 \\
\hline Number CF off & $2 \cdot 1$ & $2 \cdot 1$ & 0.34 & 0.95 & $2 \cdot 0$ & $2 \cdot 2$ & 0.33 & 0.58 \\
\hline Number CF on & $2 \cdot 3$ & 1.8 & 0.28 & 0.23 & $2 \cdot 0$ & $2 \cdot 1$ & 0.28 & 0.87 \\
\hline Piglet mortalityף & $1 \cdot 2$ & $2 \cdot 0$ & 0.31 & $0 \cdot 11$ & 1.6 & $1 \cdot 6$ & 0.31 & 0.91 \\
\hline \multicolumn{9}{|l|}{ Litter weight (kg) } \\
\hline Day 1 & $20 \cdot 8$ & $21 \cdot 5$ & $2 \cdot 25$ & 0.99 & $20 \cdot 6$ & $21 \cdot 7$ & $2 \cdot 32$ & 0.99 \\
\hline Day 14 & $57 \cdot 7$ & $56 \cdot 0$ & $2 \cdot 25$ & 0.99 & $56 \cdot 0$ & $57 \cdot 76$ & $2 \cdot 32$ & 0.99 \\
\hline Day 27 & $97 \cdot 2$ & $95 \cdot 8$ & $2 \cdot 29$ & 0.99 & 94.8 & $98 \cdot 1$ & $2 \cdot 32$ & 0.90 \\
\hline \multicolumn{9}{|c|}{$\begin{array}{l}\text { There was no gestation feeding } \times \text { lactation feeding of CAR interaction observed for any offspring measure pre-weaning, and therefore only the } \\
\text { main effects are presented in this table. Probability values at } P<0.05 \text { are considered significant and as tendencies at } P<0.10 \text {. } \\
\dagger n 32 \text { sows per treatment. } \\
\text { t Day } 27=\text { average age at weaning. } \\
\S \text { ADG is calculated on the basis of the difference in individual piglet } B W \text { at specific time points during the suckling period/number of days between } \\
\text { each time point. } \\
\text { II Litter size }=\text { number of suckling piglets in the litter. }\end{array}$} \\
\hline
\end{tabular}

CAR supplementation. Average BW at birth and at weaning of selected piglets was 1.44 (sem 0.046) kg and 8.2 (SEm 0.36) kg, respectively. There was no effect of CAR supplementation on the weight $(2.93(\operatorname{sem} 0.166) \mathrm{g})$, length $(41.7(\operatorname{SEM} 0.87) \mathrm{mm})$ or circumference $(39 \cdot 2($ SEM 0.91$) \mathrm{mm})$ of the STM measured at birth or at weaning (weight $=27 \cdot 13($ SEM 1.410$) \mathrm{g}$; length $=95 \cdot 8$ $(\operatorname{sem} 2.79) \mathrm{mm}$; circumference $=75.0(\operatorname{sem} 1.73) \mathrm{mm})$. The average myofibre area in the $\mathrm{STM}_{\mathrm{d}}$ and $\mathrm{STM}_{1}$ of the piglets slaughtered at birth was not affected by treatment, nor was the number of myofibres expressed per $\mathrm{mm}^{2}$ in the entire STM (Table 6). However, the estimated total number of myofibres in the whole STM tended to be higher in piglets from sows supplemented with CAR during gestation than in piglets from sows that received no CAR during gestation $(P=0 \cdot 08$; Table 6$)$.

\section{Enzyme activity and gene expression in the semitendinosus muscle}

The activities of HAD, CS and LDH in the $\mathrm{STM}_{\mathrm{d}}$ and $\mathrm{STM}_{1}$ of the twenty-four female piglets euthanised at birth did not differ by 
Table 6. Effect of L-carnitine (CAR) supplementation to sows during gestation on myofibre area, myofibre density (the number of myofibres expressed per $\mathrm{mm}^{2}$ ) and the estimated total number of myofibres (eTNF) in the semitendinosus muscle (STM) of female piglets at birth* (Mean values with their standard errors)

\begin{tabular}{|c|c|c|c|c|}
\hline \multirow{2}{*}{$\frac{\text { CAR }}{\text { Measure† }}$} & \multicolumn{4}{|c|}{ Gestation (mg/d) } \\
\hline & 0 & 125 & SEM & $P^{*}$ \\
\hline \multicolumn{5}{|c|}{ Average myofibre area $\left(\mu \mathrm{m}^{2}\right)$} \\
\hline STM & $106 \cdot 94$ & $102 \cdot 85$ & $7 \cdot 482$ & 0.98 \\
\hline $\mathrm{STM}_{\mathrm{d}}$ & $100 \cdot 25$ & 92.90 & 7.519 & 0.90 \\
\hline Myofibre density $\left(\times 10^{2}\right)$ & $103 \cdot 36$ & $110 \cdot 88$ & $7 \cdot 725$ & 0.51 \\
\hline eTNF $\left(\times 10^{4}\right)$ & $120 \cdot 96$ & $144 \cdot 30$ & 8.851 & 0.08 \\
\hline
\end{tabular}

STM, light portion of the STM; STM , dark portion of the STM.

* Probability values at $P<0.05$ are considered significant and as tendencies at $P<0.10$.

† $n 12$ sows per treatment. treatment, and therefore, the ratios between HAD:CS, LDH:HAD and LDH:CS were also similar (Table 7). In the $\mathrm{STM}_{1}$, piglets from sows supplemented with CAR during gestation had a tendency towards a higher expression level of MyHC IIb $(P=0.09)$ and a significantly higher expression level of $\mathrm{MyHC} \mathrm{IIx}(P=0 \cdot 02)$ compared with piglets from sows that received no CAR during gestation. The expression level of other selected MyHC genes investigated in the STM was not affected by sow treatment (Table 7).

\section{Post-weaning pig growth}

Results for PW BW, ADG, ADFI and FCE are presented in Table 8 . There was no significant interaction between dietary treatments for any variable of interest measured after weaning. Although pig BW did not differ between treatments on day 0

Table 7. Effect of L-carnitine supplementation to sows during gestation on metabolic enzyme activities characterising lipid oxidation ( $\beta$-hydroxyacyl-CoA dehydrogenase (HAD)), citric acid cycle activity (citrate synthase (CS)) and glycolytic capacity (lactate dehydrogenase $(\mathrm{LDH})$ ), and relative expression of selected myosin heavy chain genes in the dark and light portions of the semitendinosus muscle (STM) of female piglets at birth*

(Mean values with their standard errors)

\begin{tabular}{|c|c|c|c|c|c|c|c|c|}
\hline \multirow{2}{*}{$\frac{\text { STM portion }}{\text { Measure† }}$} & \multicolumn{4}{|c|}{$\mathrm{STM}_{\mathrm{d}}$} & \multicolumn{4}{|c|}{$\mathrm{STM}_{1}$} \\
\hline & 0 & 125 & SEM & $P$ & 0 & 125 & SEM & $P^{*}$ \\
\hline \multicolumn{9}{|c|}{ Metabolic enzyme activities ( $\mu \mathrm{m} / \mathrm{min})$} \\
\hline HAD & $0 \cdot 180$ & 0.166 & 0.0104 & 0.39 & 0.139 & 0.137 & 0.0116 & 0.91 \\
\hline CS & 8.416 & 8.791 & 0.3306 & 0.44 & 8.688 & 8.472 & 0.3093 & 0.64 \\
\hline LDH & 0.625 & 0.583 & 0.0329 & 0.38 & 0.528 & 0.571 & 0.0548 & 0.60 \\
\hline HAD:CS & 0.019 & 0.019 & 0.001 & 0.82 & 0.014 & 0.016 & 0.0009 & 0.17 \\
\hline LDH:HAD & 3.613 & 3.541 & 0.2144 & 0.82 & 4.193 & $4 \cdot 210$ & 0.4474 & 0.97 \\
\hline LDH:CS & 0.077 & 0.068 & 0.0061 & 0.35 & 0.069 & 0.066 & 0.0056 & 0.72 \\
\hline \multicolumn{9}{|c|}{ Gene expression analysis } \\
\hline MyHC I & 0.894 & 1.007 & 0.2811 & 0.99 & 0.618 & 0.643 & 0.2398 & 0.99 \\
\hline MyHC Ila & 0.591 & 0.639 & 0.1782 & 0.99 & 0.561 & 0.847 & 0.1782 & 0.68 \\
\hline MyHC Ilb & 0.976 & 1.019 & 0.4250 & 0.94 & 0.340 & 1.477 & 0.4371 & 0.09 \\
\hline MyHC IIx & 0.927 & 0.708 & 0.1975 & 0.45 & 0.536 & 1.055 & 0.1464 & 0.02 \\
\hline
\end{tabular}

$\mathrm{STM}_{\mathrm{d}}$, dark portion of the STM; STM, light portion of the STM; MyHC I, myosin heavy chain I; MyHC Ila, myosin heavy chain Ila; MyHC IIx, myosin heavy chain IIx; MyHC $\mathrm{Ilb}$, myosin heavy chain Ilb.

* Probability values at $P<0.05$ are considered significant and as tendencies at $P<0.10$

$\dagger n 12$ sows per treatment.

Table 8. Effect of L-carnitine (CAR) supplementation to sows during gestation and lactation on pig body weight (BW) and average daily gain (ADG) from day 0 to day 120 post-weaning (PW), and pig average daily feed intake (ADFI) and feed conversion efficiency (FCE) from day 14 to day 120 post-weaning*

(Mean values with their standard errors)

\begin{tabular}{|c|c|c|c|c|c|c|c|c|}
\hline \multirow{2}{*}{$\begin{array}{l}\text { CAR } \\
\text { Measure† }\end{array}$} & \multicolumn{4}{|c|}{ Gestation (mg/d) } & \multicolumn{4}{|c|}{ Lactation (mg/d) } \\
\hline & 0 & 125 & SEM & $P$ & 0 & 250 & SEM & $P^{*}$ \\
\hline \multicolumn{9}{|l|}{ Pig BW (kg)‡ } \\
\hline Day 0 PW & 8.0 & 8.0 & 0.12 & 1.00 & $8 \cdot 2$ & $7 \cdot 8$ & 0.12 & 0.75 \\
\hline Day 7 PW & 9.9 & $9 \cdot 4$ & 0.13 & 0.43 & 9.7 & $9 \cdot 6$ & 0.13 & 1.00 \\
\hline Day 49 PW & $35 \cdot 8$ & $34 \cdot 1$ & 0.48 & 0.41 & 34.9 & $35 \cdot 0$ & 0.48 & 1.00 \\
\hline Day 120 PW & $115 \cdot 0$ & $111 \cdot 8$ & 1.06 & 0.72 & $112 \cdot 9$ & 113.9 & 1.06 & 1.00 \\
\hline Pig ADG day 0 to day 120 PW (g/d) & 902 & 878 & $11 \cdot 3$ & 0.11 & 883 & 898 & $11 \cdot 3$ & 0.33 \\
\hline Pig ADFI day 14 to day $120 \mathrm{PW}(\mathrm{g} / \mathrm{d}) \S$ & 1670 & 1592 & $23 \cdot 4$ & 0.01 & 1624 & 1638 & 23.4 & 0.67 \\
\hline Pig FCE day 14 to day $120 \mathrm{PW}(\mathrm{g} / \mathrm{g}) \S$ & 1.79 & 1.76 & 0.027 & 0.43 & 1.78 & 1.78 & 0.027 & 0.94 \\
\hline
\end{tabular}

* There was no gestation feeding $\times$ lactation feeding of CAR interaction observed for any variable of interest measured PW, and therefore only the main effects are presented in this table. Probability values at $P<0.05$ are considered significant and as tendencies at $P<0.10$.

† Day $0 \mathrm{PW}=$ weaning; day $49 \mathrm{PW}=$ transfer from weaner accommodation to finisher accommodation; day $120 \mathrm{PW}=$ slaughter.

$\ddagger n 84$ pigs per sow treatment.

$\S$ Pig ADFI and Pig FCE could not be calculated between day 0 and day 14 PW as individual pig feed intake data were not available during this period. 
Table 9. Effect of L-carnitine (CAR) supplementation to sows during gestation and lactation on pig age, live weight and carcass quality at slaughter, carcass average daily gain (ADG) and carcass feed conversion efficiency (FCE), and lean average daily gain* (Mean values with their standard errors)

\begin{tabular}{|c|c|c|c|c|c|c|c|c|}
\hline \multirow{2}{*}{$\frac{\text { CAR }}{\text { Measure } †}$} & \multicolumn{4}{|c|}{ Gestation (mg/d) } & \multicolumn{4}{|c|}{ Lactation (mg/d) } \\
\hline & 0 & 125 & SEM & $P$ & 0 & 250 & SEM & $P^{*}$ \\
\hline Age at slaughter $(\mathrm{d})$ & $146 \cdot 5$ & $146 \cdot 6$ & 0.06 & 0.24 & $146 \cdot 5$ & $146 \cdot 5$ & 0.06 & 0.51 \\
\hline Live weight at slaughter (kg) & $115 \cdot 0$ & $111 \cdot 8$ & 1.06 & $0 \cdot 72$ & $112 \cdot 9$ & $113 \cdot 9$ & 1.06 & 1.00 \\
\hline \multicolumn{9}{|l|}{ Carcass measures } \\
\hline Weight (kg) & $86 \cdot 7$ & $83 \cdot 8$ & 0.86 & 0.01 & $85 \cdot 2$ & $85 \cdot 3$ & 0.86 & 0.90 \\
\hline Fat depth (mm) & $13 \cdot 4$ & $12 \cdot 9$ & $0 \cdot 24$ & $0 \cdot 14$ & $13 \cdot 4$ & $12 \cdot 8$ & $0 \cdot 24$ & 0.07 \\
\hline Muscle depth (mm) & $49 \cdot 2$ & $49 \cdot 6$ & 0.44 & 0.45 & $49 \cdot 4$ & $49 \cdot 4$ & 0.44 & 0.88 \\
\hline Lean meat $(\%)$ & $56 \cdot 2$ & $56 \cdot 7$ & $0 \cdot 21$ & $0 \cdot 10$ & $56 \cdot 2$ & $56 \cdot 7$ & $0 \cdot 21$ & 0.09 \\
\hline Kill out (\%) & $75 \cdot 7$ & $75 \cdot 2$ & $0 \cdot 20$ & 0.06 & $75 \cdot 7$ & $75 \cdot 2$ & 0.20 & 0.07 \\
\hline Carcass ADG $(\mathrm{g} / \mathrm{d}) \ddagger$ & 899 & 865 & $12 \cdot 3$ & 0.04 & 882 & 883 & $12 \cdot 3$ & 0.92 \\
\hline Carcass FCE $(\mathrm{g} / \mathrm{g}) \S$ & $2 \cdot 61$ & 2.59 & 0.032 & 0.45 & $2 \cdot 60$ & $2 \cdot 60$ & 0.032 & 0.94 \\
\hline Lean ADG $(g / d) \|$ & 331 & 321 & 4.7 & 0.08 & 326 & 327 & $4 \cdot 7$ & 0.83 \\
\hline
\end{tabular}

PW, post-weaning.

* There was no gestation feeding $\times$ lactation feeding of CAR interaction observed for any variable of interest measured PW, and therefore only the main effects are presented in this table. Probability values at $P<0.05$ are considered significant and as tendencies at $P<0.10$.

$\dagger n 78$ pigs on average per sow treatment.

$\ddagger$ Carcass ADG (from day $49 \mathrm{PW}$ to slaughter) was calculated as follows: carcass gain $=$ (carcass weight in $\mathrm{kg}-$ day $49 \mathrm{PW}$ weight in $\mathrm{kg} \times 0.65) \times 1000 / \mathrm{number}$ of days from day $49 \mathrm{PW}$ to slaughter(29).

$\S$ Carcass FCE was calculated as follows: carcass FCE = daily feed intake $(\mathrm{g}) /$ carcass ADG $(\mathrm{g})$.

II Lean ADG (from birth to slaughter) was calculated as follows: lean $A D G=($ carcass weight $\times$ carcass lean meat yield $\times 10) /$ age at slaughter ${ }^{(29)}$.

and day 7 PW, pigs from sows supplemented with CAR during gestation tended to be lighter on day $14 \mathrm{PW}(12.0 \quad v$. $12 \cdot 7($ sem0.15) kg; $P=0.09)$ and were significantly lighter on day 28 PW (19.4 v. 20.7 (SEM 0.25$) \mathrm{kg} ; P=0.03)$, than pigs from sows that were not supplemented with CAR during gestation. This effect was not seen thereafter. Supplementing sows with CAR during lactation had no effect on pig BW. Pig ADG between day 0 and day 120 PW was unaffected by CAR supplementation to gestating sows, despite overall pig ADFI being lower in pigs from CAR-supplemented sows during gestation than pigs from sows that were not supplemented with CAR during gestation $(P=0 \cdot 01)$. Pig ADG and ADFI were similar between sow lactation treatments. Pig FCE between day 14 and day $120 \mathrm{PW}$ was not affected by CAR supplementation to sows during gestation and/ or lactation.

\section{Carcass measures at slaughter}

Although pig live weight at slaughter was similar between sow treatment groups, pigs from sows supplemented with CAR during gestation had a lighter carcass weight than pigs from sows that were not supplemented with CAR during gestation $(P<0.05$; Table 9$)$. Consequentially, carcass ADG was reduced (calculated from day $49 \mathrm{PW}$ to slaughter; $P<0.05$ ) and lean ADG tended to be reduced (calculated from birth to slaughter; $P=0.08)$ in these pigs. These pigs also tended to have a lower kill out yield $(P=0.06)$ and tended to have a higher carcass lean meat yield $(P=0 \cdot 10)$ compared with pigs produced from sows that were not supplemented with CAR during gestation. CAR supplementation to lactating sows tended to increase carcass lean meat yield $(P=0.09)$ and tended to decrease carcass fat depth $(P=0 \cdot 07)$. CAR supplementation to sows during lactation had no effect on any other parameters of interest other than a tendency for their offspring to have a lower kill out yield at slaughter $(P=0 \cdot 07)$. Carcass FCE was not affected by treatment (Table 9).

\section{Discussion}

In the present study, no differences were found in sow BW gain during gestation or lactation in response to dietary CAR supplementation. Our results agree with previous results from our $\operatorname{group}^{(30)}$ and with a number of other sow studies ${ }^{(14,31)}$. This suggests that CAR supplementation to pregnant and lactating sows does not appear to improve the efficiency of energy utilisation, at least under conditions of adequate energy and amino acid supply. During late gestation, the BF of sows which were supplemented with CAR during gestation was consistently numerically lower than that of non-supplemented sows during gestation, with a tendency towards a lower BF observed in these sows at weaning. This suggests that dietary CAR inclusion can reduce fat deposition in sows, which may result from increased $\beta$-oxidation and thus, enhanced oxidation of dietary lipids ${ }^{(8,32)}$. Our findings of reduced sow BF are in accordance with those of Ramanau et al. ${ }^{(20)}$, but offer a direct contradiction to the findings of Musser et al. $^{(33)}$. These researchers reported an unexpected increase in last rib fat depth at weaning in CARsupplemented sows. Differences in CAR inclusion levels, sow feed allowance during gestation and dietary fat content could help to explain the dissimilar effect of CAR supplementation between these studies.

The finding that CAR supplementation to gestating sows tended to decrease plasma IGF-1 concentration on day 71 of gestation was unexpected and is inconsistent with previous reports ${ }^{(31,33)}$. These researchers found that supplementing gestating sows with 125 and $100 \mathrm{mg}$ of $\mathrm{CAR} / \mathrm{d}$, respectively, increased the IGF-1 concentration in sows' plasma during late 
pregnancy. The hormone IGF-1 is linked to animal feed intake $^{(34)}$, and fasting has the potential to significantly reduce circulating levels of IGF-1 ${ }^{(35)}$. One point to note is that the time between the last meal consumed and collection of blood samples was controlled for in the studies of Musser et al. ${ }^{(33)}$ (sows bled $6 \mathrm{~h}$ post-feeding) and Doberenz et al. ${ }^{(31)}$ (sows bled after overnight feed restriction). However, we had no control over this time variable. We acknowledge that this is a limitation of our study and therefore, we cannot disregard that the lower plasma IGF-1 concentration observed on day 71 of gestation was in fact attributable to the time in which sows consumed their last meal.

Altering the nutrition of the sow during gestation, such as providing supplemental fat, oil, CAR or conjugated linoleic acid to sows, had no influence on colostrum lactose concentration $^{(36-39)}$. The observed depression in colostrum lactose concentration in the present study is therefore very difficult to explain, and more detailed research into the effect of dietary CAR inclusion on carbohydrate metabolism in the mammary gland is required. The amount of nutrients (protein and lactose) secreted in milk has sometimes been increased when supplemental CAR was provided to sows during gestation and lactation ${ }^{(14)}$. However, neither maternal CAR supplementation during gestation nor lactation affected the nutrient concentration of sows' milk in the present study. This finding is in close agreement with findings in the recent study of Wei et al. ${ }^{(40)}$ and with the earlier findings of Ramanau et al. ${ }^{(20)}$. Thus, it can be reasoned that CAR supplementation may be ineffective at consistently influencing the metabolism of nutrients in the mammary gland, consequently resulting in a similar milk composition between sow treatment groups in the present study.

Previous results concerning the effect of CAR supplementation to pregnant sows on the number of piglets born per litter are inconsistent and possibly no longer relevant due to the significant advances in sow reproductive performance (i.e. increase in litter size) since they were carried out. Maternal CAR supplementation increased the total number of piglets born per litter in the present study, as well as numerically increasing the number of piglets born alive. Our findings compare well with those of previous studies ${ }^{(9,14,40)}$. However, the mean total number of piglets born per litter ranged from 11.7 to 12.0 in the aforementioned three studies. Thus, the prolificacy of these sows is modest relative to the highly prolific sow lines which currently predominate in the pig industry and to the sows in our study; sows in the present study had an average litter size of 16.5 total piglets born. Previous work by our group, in which supplemental CAR was fed to highly prolific gilts from day 38 of gestation (average total litter size of 14.8 piglets), observed no increase in litter size at birth ${ }^{(30)}$. The present findings therefore suggest that the effect of CAR functioned primarily during embryo implantation, which occurs during the first $35 \mathrm{~d}$ of gestation ${ }^{(41)}$. This supports the hypothesis that CAR promotes embryo viability and this beneficial effect is mediated through an improvement in in utero nutrition ${ }^{(14)}$. The mechanisms in which CAR supplementation improves in utero nutrition in sows have been reviewed in detail by
Ringseis et al. ${ }^{(42)}$, concluding that an increase in sow CAR status improves lipid and carbohydrate metabolism, which in turn improves energy generation in the tissues of sows.

In litters of hyper-prolific sows, fetuses can often suffer from inadequate prenatal nutrition which can trigger intra-uterine growth restriction and result in low-birth weight piglets ${ }^{(1,43)}$. Of importance from our study is that although litter size was increased in response to gestation feeding of CAR, mean piglet birth weight was not reduced, as might have been expected ${ }^{(15)}$. Similarly, CAR supplementation to gestating sows maintained fetal growth and development under situations of increased litter size at mid-gestation in the study of Waylan et al. ${ }^{(10)}$. In effect, this strengthens the previous assumption that dietary CAR inclusion improves in utero nutrition. Thus, the addition of CAR to sow gestation diets has potential to be utilised as an effective feeding strategy to mitigate against low-birth weight progeny in large litters. Recently, Wei et al. ${ }^{(40)}$ investigated the effect of CAR in the diet of gestating and lactating sows and found an increase in litter and mean piglet weight at birth in response to CAR inclusion. Uterine capacity is a limiting factor for fetal growth and development ${ }^{(44)}$. It can therefore be suggested that the smaller total litter size of sows in the study of Wei et al. ${ }^{(40)}$ facilitated an increase in piglet birth weight due to a larger uterine capacity, whereas an increase in fetal weight may not have been permitted in the present study due limited uterine space. It is also possible that the inclusion level of CAR used in our study, which was based on levels used in previous literature ${ }^{(11,12,14,20)}$, may be below that which is required to influence the weight of progeny at birth. The sows in the study of Wei et al. ${ }^{(40)}$ received $200 \mathrm{mg}$ of CAR/d from day 1 to day 30 of gestation, increasing to $250 \mathrm{mg}$ of CAR/d from day 30 to day 90 of gestation. The findings of Wei et al. ${ }^{(40)}$ also imply that a targeted supplementation approach with CAR yields a greater response in improving the weight of litters and piglets at birth, than supplementing sows with a consistent level of CAR throughout pregnancy.

IGF-1 is an important hormone needed for in utero fetal growth as it promotes the development of fetal muscle fibres ${ }^{(45)}$. Although a tendency towards lower IGF-1 concentrations in late gestation was observed in sows supplemented with CAR during pregnancy, a significant finding of the present study is that the STM of new-born piglets from CAR-supplemented sows during gestation appeared to be more mature at birth than the STM of piglets from non-supplemented sows. This is evidenced by the up-regulated expression of selected genes in the $\mathrm{STM}_{1}$ of these piglets at birth. An increased expression of MyHC IIb and of MyHC IIx indicates increased muscle maturation, owing to a shift towards a more glycolytic and less oxidative metabolism in the muscle ${ }^{(46)}$. Primary fibres start to express slow MyHC and mature into type I slow muscle fibres, whereas secondary fibres express fast MyHC and mature into type IIx or IIb fibres ${ }^{(47)}$. This suggests that piglets from CAR sows had a greater portion of secondary fibres in the STM at birth than piglets from non-supplemented sows, further implying increased differentiation and maturity in the muscle of these piglets in response to $\mathrm{CAR}^{(48)}$. Indeed, a tendency towards a greater estimated total number of myofibres was 
apparent in the STM of female piglets from CAR-supplemented sows. Our work confirms the earlier sow study of Musser et $a l .{ }^{(17)}$, in which supplementing pregnant sows with CAR stimulated prenatal myofibre formation. Taken together, our results confirm our hypothesis that dietary CAR supplementation to gestating sows can enhance the rate at which the muscle develops and matures in neonatal progeny.

Published literature has shown that pigs that display a reduced number of muscle fibres at birth may have poorer carcass quality at market age, as indicated by fatter carcasses ${ }^{(6)}$. The tendency towards increased carcass lean meat yield in the present study may be explained by pigs from sows supplemented with CAR during gestation having a tendency towards a greater estimated total number of myofibres at birth. It is much more likely, however, that the observed increase in carcass lean meat yield is because these pigs were lighter at slaughter. A recent study by our group observed heavier live weights and carcass weights and increased carcass muscle depth in pigs at market age (day 147) from CAR-supplemented gilts ${ }^{(30)}$, and it was hypothesised that this was largely due to increased myofibre hyperplasia. The increased total fibre number observed at birth in the present study, however, did not translate into a greater potential for these pigs to gain muscle in later life. In fact, the opposite was the case; these pigs had a lower carcass ADG and a lighter carcass at slaughter. Generally, the weight of piglets at birth and weight at weaning are strong predictors of PW growth performance ${ }^{(49)}$. As birth and weaning weights were similar between sow dietary treatments in the present study, the finding of reduced carcass weight at slaughter of pigs from sows supplemented with CAR during gestation indicates that the performance of these pigs was compromised during the PW growth period. This is confirmed by the lower PW feed intakes observed in pigs from CAR-supplemented sows, which could have contributed to the impaired growth performance during this period. The reduction in pig feed intake was highly unanticipated as management and feeding practices were similar for all pig groups, and sow treatments were equally represented in all pens PW.

\section{Conclusion}

In conclusion, CAR supplementation to gestating sows increased the total number of piglets born per litter, without compromising mean piglet birth weight. Furthermore, the STM of new-born female piglets of sows that were supplemented with CAR during gestation was more developed at birth. Carcass lean meat yield at market age tended to be increased in the progeny of sows that received supplemental CAR during gestation and lactation. However, carcass lean ADG tended to be decreased, and carcass weight and carcass kill out yield at slaughter were reduced in the progeny of sows fed supplemental CAR. The CAR supplementation strategy applied during gestation in this study could be utilised by commercial pork producers to increase sow litter size and to improve offspring muscle development at birth; however, this is at the expense of reduced carcass weight at slaughter.

\section{Acknowledgements}

The authors would like to thank Tomas Ryan, David Clarke, our visiting summer students Rachel Linn and Maxime Joubin, and the farm staff at the Pig Development Department for their assistance with pig management and data collection. In particular, we wish to thank John Walsh, Pat Magnier, Henry Allen, John Heffernan and Dan O'Donovan. The authors would like to express sincere thanks to Carmen Vonnez and Tamara Gobet (Agroscope, Posiuex, Switzerland) for their help with the histochemistry, enzyme activity and gene expression analysis. The authors also thank Jimmy Flynn and Anne Marie McAuliffe (Teagasc, Co. Cork, Ireland) for their help with the analysis of colostrum and milk.

This work was finically supported by the Department of Agriculture, Food and the Marine (DAFM) FIRM/RSF/CoFoRD 2013 Research Call (grant no. 13S428). The DAFM had no role in the design, analysis or writing of this article.

The authors contributions are as follows: H. B. R., K. O'D., J. V. O'D. and P. G. L. contributed to the conception and design of the study; H. B. R. conducted the research and collected the data; H. B. R. and K. O'D. analysed the data; H. B. R. wrote the original draft of the article; H. B. R., K. O'D., P. S., G. B., J. V. O'D. and P. G. L. reviewed, edited and approved the final article; K. O'D., J. V. O'D. and P. G. L. supervised the PhD candidate; K. O'D. and P. G. L. did project administration; and P. G. L. acquired the funding for this study and is the corresponding author.

The authors declare that there are no conflicts of interest.

\section{Supplementary material}

For supplementary material referred to in this article, please visit https://doi.org/10.1017/S0007114520000811

\section{References}

1. Beaulieu AD, Aalhus JL, Williams NH, et al. (2010) Impact of piglet birth weight, birth order, and litter size on subsequent growth performance, carcass quality, muscle composition, and eating quality of pork. J Anim Sci 88, 2767-2778.

2. Rehfeldt C \& Kuhn G (2006) Consequences of birth weight for postnatal growth performance and carcass quality in pigs as related to myogenesis. J Anim Sci 84, 113-123.

3. Foxcroft GR, Dixon WT, Novak S, et al. (2006) The biological basis for prenatal programming of postnatal performance in pigs. J Anim Sci 84, E105-E112.

4. Bauer R, Walter B, Brust P, et al. (2003) Impact of asymmetric intrauterine growth restriction on organ function in newborn piglets. Eur J Obstet Gynecol Reprod Biol 110, 40-49.

5. Alvarenga ALN, Chiarini-Garcia H, Cardeal PC, et al. (2013) Intra-uterine growth retardation affects birthweight and postnatal development in pigs, impairing muscle accretion, duodenal mucosa morphology and carcass traits. Reprod Fertil Dev 25, 387-395.

6. Lösel D, Kalbe C \& Rehfeldt C (2009) L-Carnitine supplementation during suckling intensifies the early postnatal skeletal myofiber formation in piglets of low birth weight. J Anim Sci 87, 2216-2226. 
7. Keller J, Ringseis R, Priebe S, et al. (2011) Dietary L-carnitine alters gene expression in skeletal muscle of piglets. Mol Nutr Food Res 55, 419-429.

8. Bee G (2017) Gestational strategies affecting sow reproduction and piglet birth weight. In Proceedings of the 11th International Symposium Modern Trends in Livestock Production, Belgrade, Serbia, 11-13 October 2017, pp. 121-145.

9. Ramanau A, Kluge H, Spilke J, et al. (2008) Effects of dietary supplementation of L-carnitine on the reproductive performance of sows in production stocks. Livest Sci 113, 34-42.

10. Waylan AT, Sissom EK, Starkey JD, et al. (2005) Effects of L-carnitine on fetal growth and the IGF system in pigs. J Anim Sci 83, 1824-1831.

11. Eder K, Ramanau A \& Kluge H (2001) Effect of L-carnitine supplementation on performance parameters in gilts and sows. J Anim Physiol Anim Nutr 85, 73-80.

12. Ramanau A, Kluge H, Spilke J, et al. (2002) Reproductive performance of sows supplemented with dietary L-carnitine over three reproductive cycles. Arch Anim Nutr 56, 287-296.

13. Brown KR, Goodband RD, Tokach MD, et al. (2008) Effects of feeding L-carnitine to gilts through day 70 of gestation on litter traits and the expression of insulin-like growth factor system components and L-carnitine concentration in foetal tissues. J Anim Physiol Anim Nutr 92, 660-667.

14. Ramanau A, Kluge H, Spilke J, et al. (2004) Supplementation of sows with L-carnitine during pregnancy and lactation improves growth of the piglets during the suckling period through increased milk production. J Nutr 134, 86-92.

15. Woodworth JC (2018) L-Carnitine for sows: 25 years of research-developed applications. In Animal Nutrition Conference of Canada, "Cutting edge nutritional strategies for improving performance, profitability and sustainability', Edmonton, Canada, 2-3 May 2018.

16. Prunier A, Heinonen M \& Quesnel H (2010) High physiological demands in intensively raised pigs: impact on health and welfare. Animal 4, 886-898.

17. Musser RE, Goodband RD, Owen KQ, et al. (2001) Determining the effect of increasing L-carnitine additions on sow performance and muscle fiber development of the offspring. J Anim Sci 79, Suppl. 2, 65.

18. National Research Council (2012) Nutrient Requirements of Swine, 11th ed. Washington, DC: The National Academies Press.

19. Noblet J \& Perez JM (1993) Prediction of digestibility of nutrients and energy values of pig diets from chemical analysis. J Anim Sci 71, 3389-3398.

20. Ramanau A, Kluge H \& Eder K (2005) Effects of L-carnitine supplementation on milk production, litter gains and back-fat thickness in sows with a low energy and protein intake during lactation. BrJ Nutr 93, 717-721.

21. Department of Agriculture and Food and Rural Development (2001) European Communities (Pig Carcase (Grading)) Regulations. In SI 413. Dublin, Ireland.

22. Rooney HB, O'Driscoll K, O'Doherty JV, et al. (2020) Effect of increasing dietary energy density during late gestation and lactation on sow performance, piglet vitality, and lifetime growth of offspring. J Anim Sci 98, skz379.

23. Boyd RD, Castro GC \& Cabrera RA (2002) Nutrition and management of the sow to maximize lifetime productivity. Adv Pork Prod 13, 47-59.

24. Gu XL, Song ZH, Li H, et al. (2019) Effects of dietary isomaltooligosaccharide and Bacillus spp. supplementation during perinatal period on lactational performance, blood metabolites, and milk composition of sows. J Sci Food Agric 99, 5646-5653.
25. Madsen JG, Mueller S, Kreuzer M, et al. (2017) Milk replacers supplemented with either L-arginine or L-carnitine potentially improve muscle maturation of early reared low birth weight piglets from hyperprolific sows. Animal 12, 43-53.

26. Ye J, Coulouris G, Zaretskaya I, et al. (2012) Primer-BLAST: a tool to design target-specific primers for polymerase chain reaction. BMC Bioinf 13, 134

27. Hellemans J, Mortier G, De Paepe A, et al. (2007) qBase relative quantification framework and software for management and automated analysis of real-time quantitative PCR data. Genome Biol 8, R19.

28. National Research Council (1998) Nutrient Requirements of Swine, 10th ed. Washington, DC: The National Academies Press.

29. Lawlor P \& Lynch P (2005) Effect of sow feed intake during gestation on the growth performance of progeny to slaughter. Arch Anim Breed 48, 48-55.

30. Rooney HB, O’Driscoll K, O'Doherty JV, et al. (2019) Effect of $\mathrm{L}$-carnitine supplementation and sugar beet pulp inclusion in gilt gestation diets on gilt live weight, lactation feed intake, and offspring growth from birth to slaughter. J Anim Sci $\mathbf{9 7}$, 4208-4218.

31. Doberenz J, Birkenfeld C, Kluge H, et al. (2006) Effects of $\mathrm{L}$-carnitine supplementation in pregnant sows on plasma concentrations of insulin-like growth factors, various hormones and metabolites and chorion characteristics. J Anim Physiol Anim Nutr 90, 487-499.

32. Coffey MT, Shireman RB, Herman DL, et al. (1991) Carnitine status and lipid utilization in neonatal piglets fed diets low in carnitine. J Nutr 121, 1047-1053.

33. Musser R, Goodband R, Tokach M, et al. (1999) Effects of $\mathrm{L}$-carnitine fed during gestation and lactation on sow and litter performance. J Anim Sci 77, 3289-3295.

34. He J, Zheng W, Lu M, et al. (2019) A controlled heat stress during late gestation affects thermoregulation, productive performance, and metabolite profiles of primiparous sow. J Therm Biol 81, 33-40.

35. Rahmani J, Kord Varkaneh H, Clark C, et al. (2019) The influence of fasting and energy restricting diets on IGF-1 levels in humans: a systematic review and meta-analysis. Ageing Res Rev 53, article no. 100910.

36. Jackson JR, Hurley WL, Easter RA, et al. (1995) Effects of induced or delayed parturition and supplemental dietary fat on colostrum and milk composition in sows. J Anim Sci $\mathbf{7 3}$, 1906-1913.

37. Laws J, Amusquivar E, Laws A, et al. (2009) Supplementation of sow diets with oil during gestation: sow body condition, milk yield and milk composition. Livest Sci 123, 88-96.

38. Krogh U, Flummer C, Jensen SK, et al. (2012) Colostrum and milk production of sows is affected by dietary conjugated linoleic acid. J Anim Sci 90, 366-368.

39. Birkenfeld C, Kluge H \& Eder K (2006) Nutrient composition and concentrations of immunoglobulins in milk of sows supplemented with L-carnitine. Arch Anim Nutr 60, 333-340.

40. Wei B, Meng Q, He S, et al. (2018) Effects of L-carnitine in the distillers dried grains with solubles diet of sows on reproductive performance and antioxidant status of sows and their offspring. Animal 13, 1-10.

41. Haen SM, Heinonen M, Kauffold J, et al. (2019) GnRH-agonist deslorelin implant alters the progesterone release pattern during early pregnancy in gilts. Reprod Domest Anim $\mathbf{5 4}$, 464-472.

42. Ringseis R, Keller J \& Eder K (2018) Basic mechanisms of the regulation of L-carnitine status in monogastrics and efficacy 
of L-carnitine as a feed additive in pigs and poultry. $J$ Anim Physiol Anim Nutr 102, 1686-1719.

43. Campos PHRF, Silva BAN, Donzele JL, et al. (2011) Effects of sow nutrition during gestation on within-litter birth weight variation: a review. Animal 6, 797-806.

44. Berard J, Pardo CE, Bethaz S, et al. (2010) Intrauterine crowding decreases average birth weight and affects muscle fiber hyperplasia in piglets. J Anim Sci $\mathbf{8 8}, 3242-3250$.

45. Wigmore PM \& Strickland NC (1983) DNA, RNA and protein in skeletal muscle of large and small pig fetuses. Growth $\mathbf{4 7}$, $67-76$

46. Madsen JG, Seoni E, Kreuzer M, et al. (2018) Influence of $\mathrm{L}$-carnitine and $\mathrm{L}$-arginine on protein synthesis and maturation of the semitendinosus muscle of lightweight piglets. J Anim Physiol Anim Nutr 102, 440-451.

47. Bee G (2004) Effect of early gestation feeding, birth weight, and gender of progeny on muscle fiber characteristics of pigs at slaughter. J Anim Sci 82, 826-836.

48. Rehfeldt C, Lefaucheur L, Block J, et al. (2012) Limited and excess protein intake of pregnant gilts differently affects body composition and cellularity of skeletal muscle and subcutaneous adipose tissue of newborn and weanling piglets. Eur J Nutr 51, 151-165.

49. Douglas SL, Edwards SA, Sutcliffe E, et al. (2013) Identification of risk factors associated with poor lifetime growth performance in pigs. J Anim Sci 91, 4123-4132. 